\title{
Development of Guided Inquiry Learning Module using Promting Probing Technique in Electrolyte and Non- Electrolyte Solution to Increase Thingking Ability Critical Participant in Class X in Senior High School
}

\author{
Suha Kamilah ${ }^{*}$, Hardeli², Umar Kalmar Nizar ${ }^{2}$, Desy Kurniawati², \\ ${ }^{1}$ Magister Student of Chemical Education Padang State University \\ ${ }^{2}$ Lecturer in Chemistry at Padang State University
}

\begin{abstract}
The purpose of this to produce guided inquiry inquiry electrolyte and non-electrolyte chemistry chemistry modules with probing techniques and determine the level of validity, practicality and use of modules. This research includes education development research (EDR) using the Plomp development model which has three stages, namely the initial research stage (preliminary research stage), the prototype making stage (the prototyping stage) and the renewal stage (the assessment stage). When making prototypes self-evaluation (self-evaluation), expert evaluation (expert review), individual evaluation (oneto-one evaluation), small group evaluation (small group evaluation), while testing is done through the field test (field test) in 2 schools namely SMAN 3 Payakumbuh and SMAN 5 Payakumbuh The research instrument used was a questionnaire in the form of validity and practicality sheets, multiple choice questions and critical thinking descriptions. The results of practicality by students in small groups with an average of 0.89 and practicality by teachers on average 0.90 on the field test is very high. Hypothesis test results show a significant difference between the learning outcomes of experimental class students and the control class in schools with low ability, Hypothesis test results also show a significant difference between the thinking ability of the experimental class and the control class, both in schools with moderate to low student abilities.
\end{abstract}

Keywords:- Module, Electrolyte Solution And Non Electrolyte Solution, Guided Inquiry, Probing Prompting Technique, Critical Thinking.

\section{INTRODUCTION}

The development of science and technology of Curri culum 2013 prepared which preparing Indonesian people so that havethe ability tolive as aprivate and citizensof count ries who havefaith, productive, creative, innovative, an d affective ${ }^{[1]}$. The 2013 curriculum also guides learnercentered learning that is no longer teacher-centered, so students are required to be active in the learning process.
Critical thinking is an ability that is essential for life and functions effectively in all aspects of life. Is one component in the higher level thinking process, using the basis of analyzing arguments and bringing insight into each meaning and interpretation, to develop a cohesive and logical pattern of reasoning ${ }^{[2]}$. General characteristics of critical thinking are seeing things from various perspectives and dimensions, open to change and innovation, seeing things with prejudiced thinking, open-minded, analytical thinking and paying attention to details of something ${ }^{[3]}$.

Chemistry class X SMA second semester regarding the subject matter of electrolyte and non-electrolyte solutions, students are required to understand abstract concepts. So, it takes a strong imagination of students to analyze and read the subject matter. These concepts include: signs of electrical conductivity through solutions, identifying the properties of electrolyte and non-electrolyte solutions, grouping solutions into strong electrolyte solutions, weak electrolyte solutions and non-electrolyte solutions based on the conductance of electricity.

The results of observations and interviews with several chemistry teachers and students SMA 3 and SMA 5 in Payakumbuh learning still use textbooks, worksheets, teaching materials. The teacher also uses modules in learning. The use of teaching materials, worksheets, and this module the scope of material developed is still very simple. Meanwhile, the use of complete textbooks is still limited. Thus, students use different books to complete the limitations of the book. Learners find it difficult to study independently. Students also have difficulty in analyzing critical thinking questions given by the teacher. This shows the students' critical thinking skills still need to be improved.

One suitable learning model applied in 2013 curriculum learning is the guided inquiry learning model. Inquiry-based learning is learning that helps students discover scientific concepts. According to Hanson guided inquiry is a strategy because it provides a methodology and structure of how to learn and the desired results. This guided inquiry strategy emphasizes the activities of learners to the maximum to search for and find answers to a 
problem in question. This strategy recognizes that people learn by building understanding based on initial knowledge; follow the learning cycle of exploration, concept formation, and application; discuss and interact with others ${ }^{[4]}$.

States that inquiry is a series of learning that activates students because the teacher does not transfer the learning material by presenting it in full, but the teacher provides knowledge with problem solving and a guiding question system $^{[5]}$. inquiry learning model is a learning model that requires students to be able to not only answer questions or get the right answers but are required to conduct a series of investigations, explorations, searches, experiments, searches, and research. Based on these explanations, it can be concluded that inquiry learning places teachers not as learning resources, but rather as facilitators and learners' learning motivators ${ }^{[6]}$.

Guided inquiry learning is a student-centered strategy, students work in small groups with individual roles to ensure that all students are fully involved in the learning process $^{[7]}$. guided inkuri learning is learning that involves students directly in a series of scientific learning and the results of exploration are unknown to students and learners who actively find out ${ }^{[8]}$.

Probing prompting is a learning technique presented by the teacher by giving questions that are probing and guiding students so that a thought process occurs that can link students' knowledge and experience with new knowledge that is being learned. Probing prompting learning techniques can also be said as learning that refers to increasing students' thinking power to be more active, and able to develop the ability to express opinions for students so that their knowledge becomes wider ${ }^{[9]}$.

Probing prompting learning technique is also learning that is able to develop and improve students' critical thinking skills, because in the learning process students are directly involved. Students are given a series of questions ranging from simple questions to questions with a higher level that connects students' knowledge and experience with new knowledge being learned. The questions given to students can lead students to always think and develop their thinking skills to be higher and build their own knowledge so that students can understand the subject matter well. The ability to think at a higher level is critical thinking ability $^{[10]}$.

The learning process is certainly needed teaching materials. The selection of teaching materials with the right learning model or method can support the success of the learning process ${ }^{[11]}$. There are three reasons for the need for the development of teaching materials, namely the availability of teaching materials in accordance with curriculum demands ${ }^{[12]}$. target characteristics and learning problem demands ${ }^{[13]}$.

The results of a study conducted by Diasputri, Nurhayati and Sugiyo (2013) about the effect of structured probing-prompting learning models with structured worksheets on learning outcomes show that LKB-assisted probing-prompting learning models affect student learning outcomes on Hydrocarbon and Petroleum subject matter by contributing by $32 \%{ }^{[14]}$.

Guided inkuiry based learning modules using probing prompting techniques can be an alternative to solving these problems. The module is equipped with teaching material that contains questions that guide students to think critically which are facilitated and motivated by the teacher in learning.

\section{RESEARCH METHOD}

This type of research is education development research (EDR). In this research, the development of discovery learning redox reaction module based on discovery learning using probing prompting technique to improve the critical thinking skills of high school students in class X. The development model used in this study uses the Plomp model design as developed by Tjeerd Plomp. This model consists of 3 stages, namely preliminary research (preliminary research), the stage of developing or making a prototype (development or prototyping phase) and the assessment phase (Plomp, 2013: 30). The needs analysis was done by interviewing 2 Payakumbuh 3 high school chemistry teachers and 2 Payakumbuh high school 5 teachers. Students' analysis was conducted with a study of the characteristics of the students, giving questionnaires to 60 students.

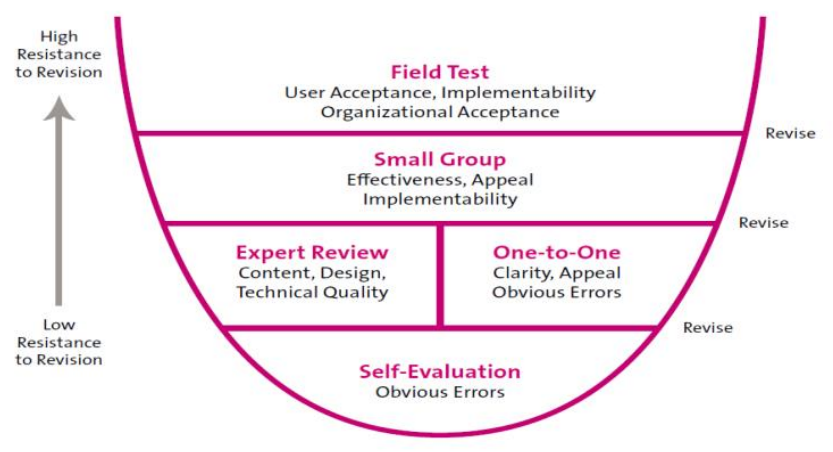

Fig 1:- Fomative Evaluation Layer (Plomp, 2013: 36)

Based on Fig 1 the formative evaluation layers used in this study are as follows:

$>$ Self-evaluation, using a checklist of important characteristics or design specifications.

$>$ Expert reviews, expert groups (subject matter experts, learning design experts) provide assessments and suggestions for the products being developed.

$>$ Individual evaluation (one-to-one evaluation), three users use the product in normal situations. Evaluators observe and interview respondents.

> Small or micto evaluation, a small group of users using the product in normal situations. Evaluators observe and interview respondents.

$>$ Field trials (group tests), a group of users use the product in actual conditions to find out the practicality and effectiveness of the product. 
The research design used was the research "Non Equivalent Control Group Postest Only Design". This design can be described as the following table (Lutfi, 2005: 69).

\begin{tabular}{|c|c|c|}
\hline & Treatment & Final Test \\
\hline Experiment & $\mathrm{X}$ & $\mathrm{T}$ \\
\hline Control Class & $\mathrm{Y}$ & $\mathrm{T}$ \\
\hline
\end{tabular}

Table 1:- Design of Field Trial Execution

\author{
Information: \\ X: Learning with modules \\ Y: Learning without modules \\ Q: Final Test
}

Analysis of critical thinking skills is done by giving a score on the answers given. Scoring is based on the assessment rubric which is modified from the following Finken and Ennis (Zubaidah, 2015: 211).

\begin{tabular}{|c|c|}
\hline Scores / Points & Descriptors \\
\hline 5 & $\begin{array}{l}\text { - All concepts are true, clear and specific } \\
\text { - All answers are correct, clear and specific, supported by strong, true, clear arguments } \\
\text { - Flow of good thinking, all concepts are interrelated and integrated } \\
\text { - Grammar is good and right } \\
\text { - All aspects appear, evidence is good and balanced }\end{array}$ \\
\hline 4 & $\begin{array}{l}\text { - } \quad \text { Most concepts are true, clear but lack specificity } \\
\text { - } \quad \text { Most of the answers are correct, clear, but lack specificity } \\
\text { - } \\
\text { - } \\
\text { - } \\
\text { Good thinking flow, most concepts are interrelated and integrated } \\
\text { All aspects appear, but not yet balanced }\end{array}$ \\
\hline 3 & $\begin{array}{l}\text { - A few concepts are true and clear } \\
\text { - A small part of the answer description is true and clear but the reasons and arguments are unclear } \\
\text { - The flow of thinking is quite good, a few are interrelated } \\
\text { - Grammar is quite good, there are spelling mistakes } \\
\text { - Most aspects that seem right }\end{array}$ \\
\hline 2 & $\begin{array}{l}\text { - Concepts are lacking focus or excessive or dubious } \\
\text { - The description of the answer does not support } \\
\text { - The flow of thinking is not good, the concepts are not interrelated } \\
\text { - Good grammar, incomplete sentences } \\
\text { - A few aspects that seem right }\end{array}$ \\
\hline 1 & $\begin{array}{l}\text { - All concepts are incorrect or insufficient } \\
\text { - The reason is incorrect } \\
\text { - The flow of thinking is not good } \\
\text { - Grammar is not good } \\
\text { - Overall aspects are insufficient }\end{array}$ \\
\hline 0 & - There are no answers or wrong answers \\
\hline
\end{tabular}

Table 2:- Modified Critical Thinking Rubric of Finken and Ennis

\section{RESULTS}

\section{A. Description of research}

The results of the content component analysis show that aspect number $1,2,3,4,5$ have very high validity. The average kappa moment for the prototype II component contents of the guided inquiry electrolyte and nonelectrolyte solution module with probing prompting technique was found to be 0.92 in the kevali category and very high.

The results of the construct component analysis show that aspects number 7 and 10 have high validity. Then the aspect $6,8,11,12$, and 13 have kevalitan and average moments kappa to construct the prototype II module component electrolyte solution and non elektrol i t based guided inquiry with the technique of probing prompting get a value of 0.90 with the validity of the category of very low.

The results of the analysis of linguistic components show that all aspects have very high validity. The average kappa moment for the prototype II linguistic component of the guided inquiry electrolyte solution and electrolyte based guided probing technique was 0.94 with a very high validity category. The analysis of the graphic components shows that all aspects have high validity. 
Component analysis showed aspects of number 19, 20, 21 have the same validity high. The average kappa moment for the prototype component II prototype module of electrolyte and non-electrolyte solution guided by guided inquiry with probing prompting technique was 0.84 with high category. Participation was the result of the evaluation of each aspect given by the validator. Based on the results of the analysis of the four components of the assessment of the prototype II module, namely the content, construct, linguistic and graphic components, the overall validation results obtained can be seen in Table 1.

\begin{tabular}{|c|c|c|c|}
\hline No & Rated aspect & K & Validity Category \\
\hline 1 & Component Contents & 0.92 & Very high \\
\hline 2 & Component Construction & 0.90 & Very high \\
\hline 3 & Language Components & .94 & Very high \\
\hline 4 & Graphing Components & .84 & Very high \\
\hline & Average & $\mathbf{0 . 9 0}$ & Very high \\
\hline
\end{tabular}

Table 3:- Results of the Overall Prototype II Assessment Analysis

The results of the analysis of prototype II assessment data for guided inquiry electrolyte and non-electrolyte solution modules with probing prompting technique as a whole showed a kappa moment value of 0.90 with a very high validity category. This shows this module has a very high level of practicality.

This assessment phase aims to see the practicality and effectiveness of the modules that are tested on large groups (field tests). Large group trials were conducted at Payakumbuh N 3 High School and Payalumbuh High School 5. In each school there are two sample classes namely the experimental class and the control class. Practicality data is obtained from giving questionnaires to students (student questionnaire responses) and chemistry teachers (teacher questionnaire responses) after implementing the learning process using modules.
Module Practicality from Student Response Questionnaire

Questionnaire responses of students filled by 58 students after learning to use modules. Based on the results of data processing questionnaire responses of students, the results obtained from the module practicality data analysis at the fieldtest stage. The average acquisition of kappa moments for practicality from student questionnaire responses was 0.89 with a high level of practicality.

Module effectiveness is seen from the learning outcomes (cognitive aspects), and students' critical thinking skills.

\section{- Learning outcomes}

The effectiveness of the module in terms of learning outcomes can be seen by comparing the learning outcomes of experimental class learning using modules with control classes that do not use modules. Trials were conducted at two medium and low category schools.

\begin{tabular}{|c|c|c|c|c|}
\hline Class & N & $\begin{array}{c}\text { Average } \\
\text { pretest }\end{array}$ & $\begin{array}{c}\text { Average } \\
\text { posttest }\end{array}$ & S \\
\hline Experiment 1 & 30 & 21.77 & 85,13 & 8,253 \\
\hline Control 1 & 28 & 21.39 & 77.64 & 10,001 \\
\hline Experiment 2 & 24 & 18.96 & 82.58 & 10,525 \\
\hline Control 2 & 22 & 19.05 & 76.77 & 12,716 \\
\hline
\end{tabular}

Table 4:- Sample Class Learning Outcomes

To determine the effect of the use of modules on the learning outcomes of pesera, a hypothesis test was conducted. Before testing the hypothesis, a normality and homogeneity test for the sample class is done from the test scores of the learning outcomes that have been obtained.

\begin{tabular}{|c|c|c|c|c|c|}
\hline Class & N & X & St.Dev & Asymp. Sig & Decision \\
\hline Experiment 1 & 30 & 85,13 & 8,253 & Reject $\mathrm{H}_{0}$ \\
\hline Control 1 & 28 & 77.64 & 10,001 & & Reject $\mathrm{H}_{0}$ \\
\hline Experiment 2 & 24 & 82.58 & 10,525 & .000 & \\
\hline Control 2 & 22 & 76.77 & 12,716 & & \\
\hline
\end{tabular}

Table 5:- Hypothesis Test Results for Sample Classes 
If the significance value $>0.05$, accept $\mathrm{H}_{0}$ and vice versa. The decision to reject $\mathrm{H}_{0}$ means the learning outcomes of students with critical thinking skills who learn by using modules and without modules differ significantly. The average learning outcomes of students who use modules are higher than students who do not use modules. Decision accept $\mathrm{H} 0$ means the study of students with critical thinking skills that are taught using modules and no module did not differ significantly. The average learning outcomes of students who use modules are higher than students who do not use modules.

The presence or absence of interactions between the use of guided inquiry electrolyte and non-electrolyte modules with school level probing prompting techniques in influencing learning outcomes is known from the results of the two-way ANOVA test. Based on these Figs it is known that there is no interaction between the use of modules and school level in influencing student learning outcomes. This can be seen from the absence of intersecting lines shown in Fig 2 .

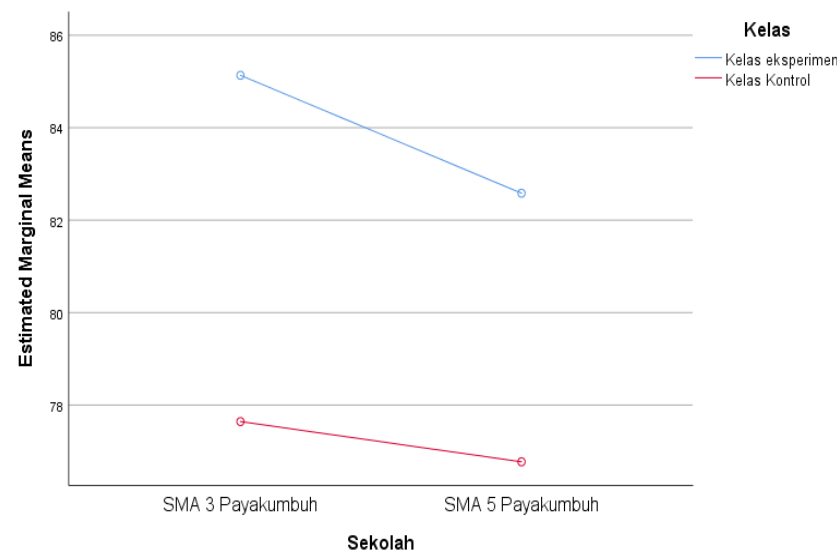

Fig 2:- Interaction between the use of modules and school level in influencing learning outcomes.

Based on Fig 2, it is found that both moderate and low school categorized schools learning using modules affect the learning outcomes of students.

Schools with a medium category using modules have more influence on student learning outcomes, so the use of modules is more suitable for medium category schools. This is because schools in the medium category are accustomed to independent learning and have a stronger desire to learn.

\section{- Critical Thinking Ability}

The ability to think critically is seen from five aspects, namely providing a basic explanation ( basic clarification), making the basis of a decision (the bases for a decision), making conclusions (inferences ), providing advanced explanations ( advanced clarification ) and regulating strategies and tactics ( strategy and tactics) ). Students' critical thinking skills can be seen from the ability of students to answer questions that are designed based on indicators of critical thinking.

Persentase critical thinking skills experimental class and control class in every aspect of critical thinking indicators both schools seseuaikan with indicator aspects critical thinking skills. The results of the participant's critical thinking skills in the experimental and control classes can be seen in Fig 3.

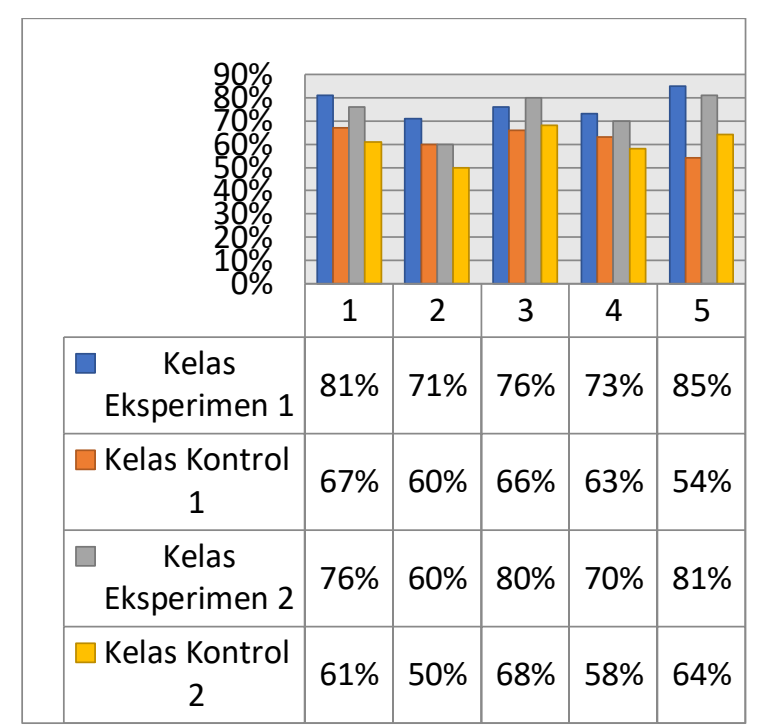

Fig 3:- Percentage of critical thinking skills of learners grade sample on every aspect of the indicator think kriti s learners

Based on Fig 3 it can be concluded that the questions no. 1 and 2 with critical thinking indicators provide the basic explanation, the highest percentage is experimental class 1 which is $81 \%$ with very good category. The second question on indicators builds the basis for making a decision the highest percentage is experimental class 1 which is $71 \%$ in the good category. The third problem with the indicators making conclusions, the highest percentage of classes is experimental class 2 which is $80 \%$ with good categories. The fourth problem by making further explanation, the highest percentage of classes is ekeprimen 1 which is $73 \%$ well. The fifth question with indicators governing strategy and tactics, the highest percentage of class is experimental class 2 which is $81 \%$ with a very good category

The influence of the use of modules on the ability to think critically was tested hypothesis. Before testing the hypothesis, a normality and homogeneity test was carried out on the sample class from the test results of the learning outcomes that had been obtained. The results of the normality and homogeneity tests of the sample classes found that the learning outcomes of the experimental class and the control class in the two schools were normally distributed where the significance value> 0.05 and had a non-homogeneous variance where the significance value $<0.05$, so the $t$ test was conducted. Hypothesis test results can be seen in Table 4 . 
ISSN No:-2456-2165

\begin{tabular}{|c|c|c|c|c|c|}
\hline Class & N & Average & St.Dev & Sig & Decision \\
\hline Experiment 1 & 30 & 26.63 & 4,657 & 0,000 & \multirow{2}{*}{ Reject $\mathrm{H}_{0}$} \\
\cline { 1 - 4 } Control 1 & 28 & 22.00 & 4,690 & & \\
\cline { 1 - 4 } Experiment 2 & 24 & 24.54 & 4,890 & \multirow{2}{*}{0,000} & Reject $\mathrm{H}_{0}$ \\
\hline Control 2 & 22 & 20.86 & 5,817 & & \\
\hline
\end{tabular}

Table 6:- Hypothesis Test Results for Sample Classes

If the significance value $>0.05$, accept $\mathrm{H}_{0}$ and vice versa. The decision to reject $\mathrm{H}_{0}$ means that the critical thinking ability of students who learn using modules and without modules differs significantly. The average critical thinking ability of students who use modules is higher than students who do not use modules.

Interaction between modulkimia use of electrolyte and non-electrolyte solution-based techniques terbimbing dengan inquiry probing prompting with school-level influences to the inability to think kritispeserta learners can be known from two-way ANOVA test results can be found no interaction between module use and school level in influencing students' critical thinking abilities . This can be seen from the absence of intersecting lines shown by the graph in Fig 4

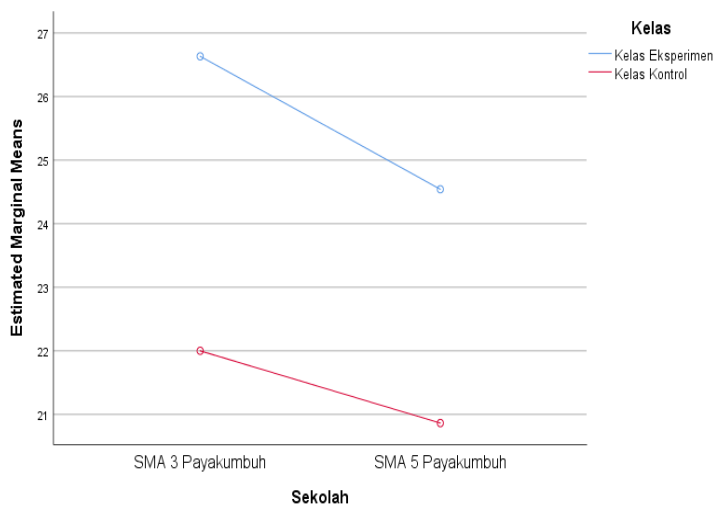

Fig 4:- The interaction between the use of modules with the school level in influencing critical thinking skills
Based on Fig 4 it can be seen that in the medium category school and the low category school the use of modules influences students' critical thinking skills. Medium category students' critical thinking skills are better than low category schools, but the use of modules is equally influential on critical thinking skills. The results of the analysis of the percentage of students' critical thinking skills can be seen in Fig 5.

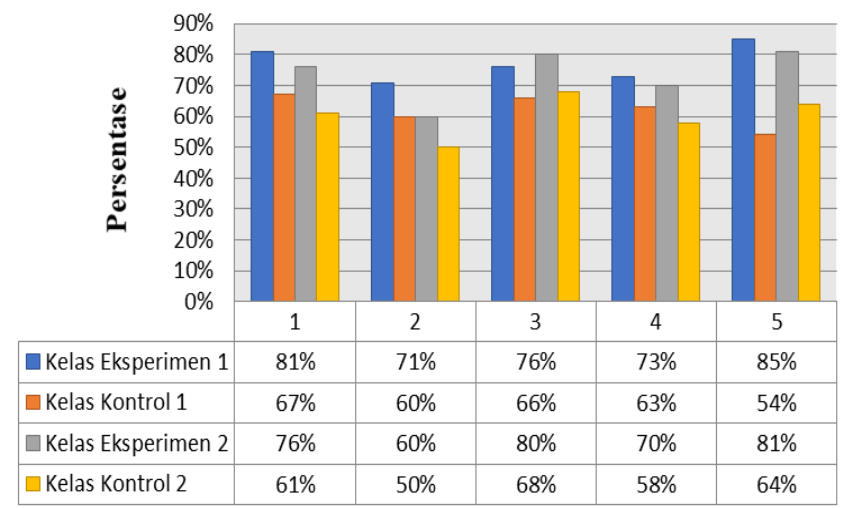

Fig 5:- Percentage of critical thinking skills of sample class students in each aspect of critical thinking indicators

Based on Fig 5 it can be seen that in schools categorized as medium and low categorized schools the use of modules is equally influential on students' critical thinking skills. Medium schools of students' critical thinking skills are better than low categorized schools. This is because students in medium schools have been seen developing critical thinking skills in aspects of critical thinking indicators.

\section{Learning activities Learners}

Learning activities assessed were students who used the guided inquiry electrolyte and non-electrolyte solution modules with probing prompting techniques. These activities are in the form of visual activities, mental activities and writing activities with a grid.

\begin{tabular}{|c|c|c|c|c|c|}
\hline NO & ACTIVITY & $\begin{array}{c}\text { EXPERIMENT } \\
\text { CLASS 1 }\end{array}$ & CATEGORY & $\begin{array}{c}\text { EXPERIMENT } \\
\text { CLASS 2 }\end{array}$ & CATEGORY \\
\hline $\mathbf{1}$ & $\begin{array}{c}\text { Observe Figs and written sources for } \\
\text { formulating problem and hypothesis }\end{array}$ & $81.94 \%$ & Very effective & $80.32 \%$ & Very effective \\
\hline $\mathbf{2}$ & Answering questions in the module & $84.49 \%$ & Very effective & $81.48 \%$ & Very effective \\
\hline $\mathbf{3}$ & Gathering Information & $84.03 \%$ & Very Effective & $81.02 \%$ & Very Effective \\
\hline $\mathbf{4}$ & Work on worksheets & $85.42 \%$ & Very Effective & $79.40 \%$ & Effective \\
\hline & Average & $84.33 \%$ & Very Effective & $81.17 \%$ & Very Effective \\
\hline
\end{tabular}

Table 7:- The results of the analysis of the experimental class learning activity data 
Learning activities of students assessed are activities in working on modules. Comparison of class E learning activities of experiments 1 and 2 can be seen in Fig 6.

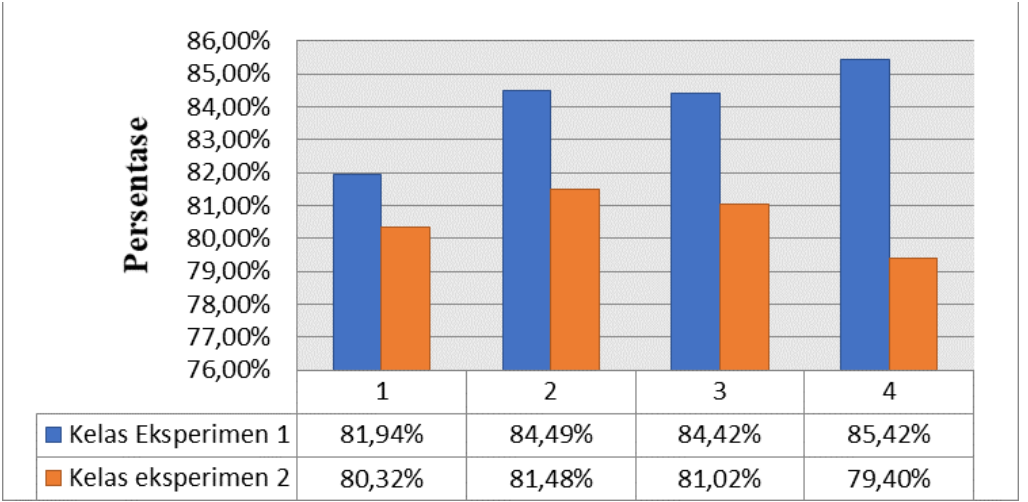

Fig 6:- Percentage of Student Learning Activities Using Modules

Based on Fig 6 the percentage of student activity in the School I stage of observing Figs and written sources to formulate problems and hypotheses is $81.94 \%$ with a very effective activity category. The percentage of learning activities of students at the stage of answering questions in the module is $84,49 \%$ with a very effective activity category. The percentage of student activity at the information gathering stage was $84.03 \%$ with the category of very effective activities. The percentage of student activity at the stage of working on the worksheet is $85.42 \%$ with a very effective activity category.

School II the percentage of student activity at the stage of observing images and written sources to formulate problems and hypotheses is $80.32 \%$ with a very effective activity category. The percentage of student activity at the stage of answering questions in the module is $81.48 \%$ with a very effective activity category. The percentage of student activity at the information gathering stage is $81.02 \%$ with the category of very effective activities. The percentage of students' activities at the worksheet stage was $79.40 \%$ with the category of effective activities. So it can be concluded that both the School I and II school learning activities of learners by using modules kimialarutan electrolyte and non-electrolyte-based inquiry terbimbingdeng a $\mathrm{n}$ technique of probing prom $p$ ting in the category very effective.

\section{Module Field Analysis}

The module content analysis aims to see the competence of students in their groups to answer each syntax of guided inquiry learning models in the module, so that each syntax in the module is answered correctly by each group. Modules in Experiment 1 and 2 classes are taught in class X MIPA 3 and X MIPA 1 by the number of students by 30 and 24 people. Students are divided into 6 groups and each group consists of 4-5 people. Evaluation of each student's answers can be seen in Table 8 .

\begin{tabular}{|c|c|c|c|c|c|}
\hline No & Syntax & Exp Class 1 & Category & $\begin{array}{c}\text { Exp } \\
\text { Class 2 }\end{array}$ & Category \\
\hline 1 & Orientation & $92 \%$ & Very well & $88 \%$ & Very well \\
\hline 2 & $\begin{array}{c}\text { Exploration and concept } \\
\text { formation }\end{array}$ & $83 \%$ & Very well & $92 \%$ & Very well \\
\hline 3 & Application & $89 \%$ & Very well & $88 \%$ & Very well \\
\hline 4 & Pe closed the & $89 \%$ & Very well & $79 \%$ & B aik \\
\hline & Average & $89 \%$ & Very well & $86 \%$ & Very well \\
\hline
\end{tabular}

Table 8:- Evaluation of Module Answers for Each Syntax in Experiment Class

Based on Table 8 it can be seen that for Experiment 1 class the orientation phase of students who answer the module contents correctly is $92 \%$, the exploration and formation stage of students who answer the module contents correctly is $92 \%$, the application stage of students who answer the module contents correctly is $89 \%$, the stage of students who answer the module contents correctly is $89 \%$. The average value of students for the whole syntax of guided inquiry in Experiment 1 class was $89 \%$ with a very good category.
Group Experiment 2 phase orientation of students who answered stuffing module correctly is $88 \%$, the stage of exploration and establishment of the concept of learners who answered stuffing module correctly is $92 \%$, the stage of the application of students who answered stuffing module correctly is $88 \%$, the stage of students who answered the module correctly was $79 \%$. The average value of students for the whole syntax of guided inquiry in Experiment 2 class was $86 \%$ with a very good category. 
The results of the analysis of each student's answer module syntax in the guided inquiry learning model as a whole value of the contents of Experiment 2 class modules are higher than the contents of Experiment 1 module modules. This is caused by the students of Experiment 2 class whose enthusiasm and desire to learn are higher than classes Experiment 1.

\section{DISCUSSION}

Product quality resulting from development research is assessed based on three aspects, namely validity, practicality and effectiveness (Nieveen, 1999: 127). The validity, practicality and effectiveness of electrolyte and non-electrolyte modules with probing prompting techniques are explained as follows.

\section{Module Validity}

The module validity data was obtained at the expert review stage ( expert review ) using validated instruments. The module design was validated by six validators, consisting of three chemistry lecturers at the Faculty of Mathematics and Natural Sciences, two chemistry teachers at SMAN 3 Payakumbuh questions and one chemistry teacher at SMAN 5 Payakumbuh.

Overall the average kappa moment acquisition for the validity of the guided inquiry electrolyte and nonelectrolyte modules guided by the probing prompting technique developed was 0.90 with a very high validity category.

\section{Practicality of Modules}

The instruments used were a questionnaire sheet practicalities given to nine students in the evaluation stage of a small group ( small group evaluation ), 58 learners experimental classes and two teachers accompanying chemistry research at the stage of field trials (field tests ).

In the small group evaluation stage, the module is tested in actual conditions with nine students having low, medium and high skills. At the end of the meeting students are asked to provide a practicality assessment of the module. In the field trial phase, the module was tested in two schools namely SMAN 3 Payakumbuh and SMAN 5 Payakumbuh.

The benefit of the module is that the practicality level is very high with a kappa moment of 0.89 in small group evaluations and 0.90 in field trials.

\section{$>$ Effectiveness of Modules}

Effectiveness is assessed based on the results of using the product as desired (Plomp, 2013: 28). If the module operationally provides results as expected, the module is said to be effective (Nieveen, 1999: 128). In this study, the effectiveness of the guided inquiry-based electrolyte solution module with probing prompting technique is seen from the learning outcomes of students (cognitive aspects), and students' critical thinking abilities.
Student learning outcomes are seen after the module has been tested in two schools, namely the medium and low category schools. Each school has two sample classes, namely the experimental class and the control class. In Appendix 58 Page 339 it can be seen that the final test results of the experimental class are higher than the control class. The difference in value is tested with a hypothesis test to find out whether differences in learning outcomes are influenced by the use of modules or not.

Hypothesis testing results in schools with medium and low categories show that learning outcomes of students who use the electrolyte and non-electrolyte solution modules guided guided inquiry with probing prompting techniques significantly higher than the learning outcomes of students who do not use modules.

Students' critical thinking skills are assessed by giving out seven critical questions in the form of critical thinking questions. The results of hypothesis testing show that the critical thinking ability of students who learn by using the guided inquiry electrolyte and non electrolyte modules guided by probing prompting techniques is significantly higher than students who do not use modules, both in schools with moderate and low categories.

\section{$>$ Module content analysis}

Module electrolyte and non-electrolyte based guided inquiry with the technique of probing prom $p$ ting tested used in the experimental class SMAN $3 \mathrm{~Pa}$ yakumbuh (school low category) and SMAN 5 P ayakumbuh (school medium category). The module uses a guided inquiry learning model with each learning syntax using probing prompting questioning techniques . The average answers given by students in the module contents in each syntax are very good for both schools.

The percentage of module contents for each syntax in both low category and medium category schools is not much different. The comparison of the percentage of school module content in the low and medium categories using the syntax of the guided inquiry learning model as a whole is $89 \%: 86 \%$. This data shows that both low category schools and medium category schools all learning groups work on module filling in very good categories.

\section{CONCLUSIONS}

This research is a research development that produces guided inquiry electrolyte and non electrolyte modules based on probing prompting techniques to improve the critical thinking skills of class $\mathrm{X}$ high school students. Based on the research that has been done, it can be concluded as follows :

(1) the result of guided inquiry electrolyte and nonelectrolyte solution modules guided by probing prompting techniques to improve the critical thinking skills of XSMA class students, (2) the results of the study showed that: (a) Guided inquiry-based electrolyte and non-electrolyte solution modules with probing prompting techniques 
produced have a very high level of validity with a kappa moment value of 0.90 . (b) The resulting module has a very high level of practicality from the results of the small group evaluation questionnaire ( small group evaluation), the field trial stage ( field test) and has a very high level of practicality from the results of the teacher response questionnaire. (c) The effectiveness of the module is seen from the comparison of student learning outcomes of the experimental class (learning by using modules) and the control class (learning without modules). Hypothesis testing shows that there are significant differences between experimental class learning outcomes and control classes with a $95 \%$ level of significance.schools with medium and low categories. (d) Hypothesis test results show the resulting module can improve learning outcomes and students' critical thinking skills. In general, student learning outcomes and critical thinking skills in the experimental class are higher than in the control class for both medium and low category schools

\section{REFERENCES}

[1]. Regulation of the Minister of Education and Culture of the Republic of Indonesia Number 69 of 2013 concerning the Basic Framework and Curriculum Structure of High Schools / Madrasah Aliyah. 2013. Jakarta: Ministry of Education and Culture.

[2]. Liliasari, 2003. Improving Teacher Quality in Higher Level Thinking Skills Through the Capita Selekta Chemistry Learning Model for High Schools. Journal of Mathematics and Science Education. Vol.3 (7): 175

[3]. Birgili, Bengi. 2015. Creative and Critical Thingking Skills in Probased Learning Environments. Journal of Gifted Education and Creativity. Vol2 (2): 71-80.

[4]. Hosnan, M. 2014. Scientific and Contextual Approaches in 21st Century Learning: Keys to Successful Implementation of 2013 Curriculum. Bogor: Graha Indonesia

[5]. Serafin, et.al . 2015. Inquiry-Based Instruction in The Context of Constructivism. Procedia - Social and Behavioral Sciences.

[6]. Abidin, Jonah. 2014. Learning System Design in the Context of Curriculum 2013. Bandung: PT Refika aditama

[7]. Straumanis, A (2010). Classroom implementation of process oriented guided inquiry learning: a practical guide for instructors. POGI. Organic Chemistry A Guided Inquiry, Second Edition.

[8]. Parappilly, ect (2013). An inquiry-based approach to laboratory experiences: Investigating students' ways of active learning. International Journal of Innovation in Science and Mathematics Education, 21(5), $42-53$.

[9]. Shoimin.2016. Innovative Learning Model. In the curriculum. 2013. Yogjakarta: Ar-ruzz Media

[10]. Julita, R., Hardeli, A. P., Yerimadesi, F. P., \& Yenti, R. 2019. I mproving Students' Critical Thinking Skills through Module Ion Equilibrium in Salt Solution Based on Discovery Learning with Probing Prompting.
[11]. Ellizar, E., Hardeli, H., Beltris, S., \& Suharni, R. (2018, April). Development of Scientific Approach Based on Discovery Learning Module. In $O P$ Conference Series: Materials Science and Engineering (p. 012101).

[12]. Ellizar, E., Putri, S. D., Azhar, M., \& Hardeli, H. (2019, April). Developing a discovery learning module on chemical equilibrium to improve critical thinking skills of senior high school students. In Journal of Physics: Conference Series (Vol. 1185, No. 1, p. 012145). IOP Publishing.

[13]. Directorate of Education Personnel. 2008. Writing Modules. Jakarta: Ministry of National Education.

[14]. Diasputri, et al. The Effect of Probing Prompting Learning Model Assisted Structured Worksheet on Learning Outcomes. UNS. Vol 6 (2): 1003-1010

[15]. Plomp, Tjeerd dan Nienke Nieveen. 2013. Educational Design Research: An Introduction. Enschede: Netherlands Institute for Curriculum Development (SLO)

[16]. Arikunto, Suharsimi. 2009. Research Management. Jakarta: Rineka Cipta. 